\title{
VỀ NHÂN VẬT PHỤ TRONG TRUYẾN KIỀU
}

\section{Lê Hồng Phong a* $^{\text {* }}$}

${ }^{a}$ Phòng Tạp chí và Truyền thông, Truờng Đại học Đà Lạt, Lâm Đồng, Việt Nam

"Tác giả liên hệ: Email: phonglh@dlu.edu.vn

\section{Lịch sử bài báo}

Nhận ngày 15 tháng 12 năm 2020 | Chấp nhận đăng ngày 12 tháng 01 năm 2021

Xuất bản trực tuyến ngày 16 tháng 4 năm 2021

\section{Tóm tắt}

Bằng phương pháp thực chứng để bám sát ngôn tù tác phẩm, bài báo nhằm nhận thức lại, nhận thức thêm về tính cách, vai trò và quan hệ của các nhân vật phụ trong "Truyện Kiều”; thấy được dụng ý của Nguyễn Du khi bỏ quên hoặc tạm lãng quên một số nhân vật phu, kể cả Kim Trọng; tác giả cũng cải chính một số nhận định sai của các nhà nghiên cưu về một vài nhân vật phu trong "Truyện Kiều".

Từ khóa: Cốt truyện; Nguyễn Du; Nhân vật phụ; Sự lãng quên; Truyện Kiều.

DOI: http://dx.doi.org/10.37569/DalatUniversity.11.2.811(2021)

Loại bài báo: Bài báo nghiên cứu gốc có bình duyệt

Bản quyền (C) 2021 (Các) Tác giả.

Cấp phép: Bài báo này được cấp phép theo CC BY-NC 4.0 


\title{
SUPPORTING CHARACTERS IN THE TALE OF KIEU
}

\section{Le Hong Phong ${ }^{a^{*}}$}

\author{
${ }^{a}$ Department of Journal and Communication, Dalat University, Lam Dong, Vietnam \\ *Corresponding author: Email: phonglh@dlu.edu.vn
}

\section{Article history}

Received: December $15^{\text {th }}, 2020 \mid$ Accepted: January $12^{\text {th }}, 2021$

Available online: April $16^{\text {th }}, 2021$

\begin{abstract}
Using the method of authentication to strictly follow the words of the work, this article reaffirms and explores the personalities, roles, and relationships of the supporting characters in "The Tale of Kieu". This exploration is intended to discover Nguyen Du's intentions when he forgets, or temporarily forgets, certain supporting characters, including Kim Trong. The author also attempts to correct certain misassumptions of other researchers about some supporting characters in "The Tale of Kieu".
\end{abstract}

Keywords: Forget; Nguyen Du; Plot; Supporting characters; The Tale of Kieu.

DOI: http://dx.doi.org/10.37569/DalatUniversity.11.2.811(2021)

Article type: (peer-reviewed) Full-length research article

Copyright $(\mathrm{C} 2021$ The author(s).

Licensing: This article is licensed under a CC BY-NC 4.0 


\section{1. ĐẶT VẤn Đ $\mathbf{̣}$}

Truyện Kiều là tác phẩm lớn trong văn học Việt Nam trung đại; lục bát Nguyễn Du là đỉnh cao khó vượt trong lịch sử thi ca Việt Nam; Thúy Kiều là nhân vật trung tâm của truyện thơ hay nhất được các nhà Kiều học và hầu hết những người giảng dạy, nghiên cứu quan tâm ở những góc độ khác nhau. Tuy vậy, khoa học là vô cùng, từ những góc nhìn mới vẫn có thể có nhận thức mới, tìm ra những nét mới, lối diễn đạt mới về văn bản, về nội dung tư tưởng và hiện thực xã hội, về đạo đức nhân sinh, về thân phận nhân vật chính trong mối quan hệ với các nhân vật phụ, về thi pháp tác phẩm và tác giả, về dư âm và dấu ấn sâu đậm của Truyện Kiều trong dân ca, thơ ca, tiểu thuyết... Riêng về các nhân vật phụ, có một số nhân vật đã được nghiên cứu trong tương quan với Kiều như Kim Trọng, Thúc Sinh, Từ Hải... Tuy nhiên, nhiều nhân vật phụ khác chỉ mới được nhắc đến khi cần nói về sự hỗ trợ hay vùi dập nhân vật chính, hoặc khi cần nhấn mạnh nội dung hiện thực, quan hệ xã hội, giá trị tố cáo của Truyện Kiều... Ở bài viết này, tác giả nhận thức lại, nhận thức thêm về các nhân vật phụ, chủ yếu trong tình cảm, thái độ và hành xử của họ với Kiều. Và vì các nhân vật là những đứa con tinh thần của tác giả có vị thế khác nhau trong tác phẩm, nên người viết đã xem xét các nhân vật ấy trong ý đồ nghệ thuật của nhà thơ Nguyễn Du. Khi cần thiết, bài báo cũng mạnh dạn đề xuất đính chính một vài luận điểm chưa chính xác của các nhà nghiên cứu về nhân vật phụ của Truyện Kiều; các công trình tiêu biểu ấy được nêu trong tài liệu tham khảo mà không đưa vào đây để bài viết được tập trung ưu tiên vào các nhân vật phụ.

\section{VƯƠNG QUAN - ÔNG QUAN BÀNG QUAN TRƯỚC GIA SỰ}

Trong gia đình Kiều, ngay từ đầu tác phẩm, Nguyễn Du đã giới thiệu đủ các nhân vật như Vương Ông, Vương Bà, Thúy Kiều, Thúy Vân, Vương Quan. Và đến kết thúc thiên truyện thơ, tác giả sẽ cho tất cả các nhân vật này được tái xuất hiện. Toàn bộ tác phẩm chủ yếu dành cho cuộc đời, tài sắc, thân phận và các quan hệ xã hội của Thúy Kiều. Về Thúy Vân ít nhiều cũng được các nhà nghiên cứu xem xét trong tương quan với tài sắc Thúy Kiều, trong việc trao duyên lúc gia biến và trả duyên khi đoàn viên. Ở đây, tác giả bài viết muốn tìm hiểu về chàng Vương Quan - người con út trong gia đình họ Vương vì các nhà nghiên cứu rất ít quan tâm đến nhân vật này.

Nguyễn Du chỉ nói ngắn gọn về "Một trai con thứ rốt lòng/Vương Quan là chũ nối dòng nho gia", không hề giới thiệu gì về phong tư, tài mạo, phẩm cách con người này. Trong tiết Thanh minh, Vương Quan tháp tùng hai chị đến lễ tảo mộ - hội Đạp Thanh. Ở đấy, Vương Quan "quen mặt ra chào" như một xúc tác vô tình, ngẫu nhiên cho Kim Trọng làm quen với cả hai chị, chưa thấy bộc lộ cảm tình riêng với chị nào, có chăng là Kiều đã cảm Kim Trọng trước. Cũng tại đây, chàng đã giới thiệu với chị Kiều về lai lịch, tài sắc và thân phận hẩm hiu của Đạm Tiên - như một tiền thân đồng điệu của Thúy Kiều. Trước sự đa cảm, đa đoan của chị, cả Vương Quan lẫn Thúy Vân đều cho là "chuyện cũng nục cười/ Khéo dur nước mắt khóc người đời so", "Một điều là một vận vào khó nghe" (Nguyễn, 2019, tr. 21).

Vương Ông, Vương Quan ngẫu nhiên thành nạn nhân của "thằng bán tơ”, bị trói, bị treo, bị hành hạ, bị tống giam. Chính Vương Quan phải chịu ơn Thúy Kiều, ai cũng 
khen Kiều quyết liệt dứt tình, chuộc cha vì hiếu, nhưng chuộc cha cũng chính là cứu em. Khi Kim Trọng rước mời gia đình Vương Ông về nuôi dưỡng do "cửa nhà sa sút" thì chính Vương Quan cũng được Kim Trọng chu cấp ăn học, cùng đi thi, cùng đậu đạt, cùng được bổ nhiệm làm quan... Đúng như Nguyễn Du đã gói gọn trong mấy chữ "nối dòng nho gia", Vương Quan là nho sĩ hành đạo đúng lộ trình: học-thi-đậu-làm quan. Sau khi đỗ đạt, Vương Quan đã đến nhà ông lại già họ Chung để tạ ơn ân nhân - kẻ môi giới cho màn hối lộ 300 lạng để chuộc cha, chuộc mình và chàng Vương trở thành con rể ông ấy...

Do quá thương yêu xót xa Kiều, do phải tập trung ưu tiên đầu tư cho nhân vật chính, Nguyễn Du không có điều kiện quan tâm đến cả gia đình Vương kể từ sau gia biến. Nói cách khác, tác giả như thể lãng quên, không dành cho Vương Quan một từ nào kể từ câu thơ 579 "Già giang một lão một trai" (Nguyễn, 2019, tr. 87) đến câu 2740 khi tác giả quay lại nói về "Nỗi chàng Kim Trọng bấy chầy mới thuoong" (Nguyễn, 2019, tr. 367). Khi Kim được cải nhậm Nam Bình thì Vương Quan cũng được cải nhậm Châu Dương, cùng hướng Chiết Giang, Phúc Kiến - nơi Từ Hải đã và đang vùng vẫy. Và Nguyễn Du đã viết câu 2955: "Được tin Kim mới rủ Vuoong" cùng đi tìm Kiều (Nguyễn, 2019, tr. 393). Trong hơn 2400 câu thơ, người đọc không hề thấy một hành vi chủ động, một lời thưa thốt, một chút xao động nội tâm nào bộc lộ rằng Vương Quan có nhớ thương đến người chị tài hoa bạc phận của mình. Trong niềm vui của cha mẹ và Vân, Kim gặp lại Kiều, không thấy Vương Quan hoan hỉ, phát ngôn gì. Mặc dù cha thuyết phục Kiều trở về nhà, mặc kệ chị Vân tự nguyện trao lại duyên, mặc cho Kim tha hồ chiêu tuyết để mong Kiều kết hôn và sống cuộc sống đời thường, Vương Quan tuyệt nhiên im lặng!

Sự lãng quên Vương Quan đó ý đồ sáng tạo và quyết định của tác giả, nhưng xét một cách khách quan khi tiếp nhận tác phẩm và tiếp cận nhân vật, Vương Quan đã thể hiện như một ông quan bàng quan, vô cảm, vô trách nhiệm trước tất thảy mọi cơn gia biển hay đại hoan hỉ của toàn gia. Vương Quan thực sự đã chết tinh thần, chết tâm hồn ngay khi được Kiều cứu chuộc.

\section{KIM TRỌNG - NGƯÒ̀I TÌNH BỊ LÃNG QUÊN}

Kim Trọng được các nhà nghiên cứu nhắc rất nhiều trong mối quan hệ KimKiều, trong mối tình đầu gắn với chủ đề tình yêu, trong quan niệm khác thường của chàng về chữ trinh trong màn đoàn viên tái hợp, để rồi đành "đem tình cầm sắt đổi ra cầm cờ" theo đề xuất của Kiều.

Kim đã hiện lên trong phần mở đầu với lời giới thiệu trang trọng của Nguyễn Du về một bậc văn nhân nho nhã, phong lưu. Chàng chủ động tìm đển trọ học gần nhà Kiều, và sau đó, chính Kiều lại chủ động, táo bạo hơn trong việc "xăm xăm băng lối vuờn khuya một minh". Mối tình đầu được xây dựng thật đẹp, khác thường, chệch khỏi quy phạm của xã hội phong kiến trung đại. Cơn gia biến nhà Kiều xảy ra trong thời gian Kim đi vắng, chàng không chứng kiến, cũng không ai báo tin (vì chưa ai biết họ đã bí mật yêu nhau), để rồi Kim-Kiều cách biệt đến 15 năm đằng đẵng... 
Nguyễn Du tập trung theo sát cuộc đời sóng gió, đau đớn của Kiều, tạm gác Kim Trọng từ câu thơ 569, mãi đến câu 2740 tác giả mới cho nhân vật này trở lại: "Nỗi chàng Kim Trọng bấy chầy mới thương" (Nguyễn, 2019, tr. 367). Gần hai nghìn hai trăm câu thơ, chiếm 2/3 tác phẩm không hề có mặt Kim. Dường như độc giả cũng bị cuốn hút vào cuộc đời tang thương dâu bể của Kiều mà quên bẵng anh chàng phong lưu hay chữ này.

Tuy cho nhân vật trở lại rất muộn màng, tác giả vẫn dành riêng một mạch phụ rất kiệm ngôn để lướt thật nhanh cho mọi người thấy cả quãng đời Kim, nỗi lòng và những việc Kim đã làm trong thời gian gần 15 năm. Ngay khi hộ tang trở về, Kim đã trở lại chốn xưa, gặp người láng giềng để hỏi thăm và đau đớn biết sự thật xảy ra trong khi mình đi vắng. Khi nghe Vương Ông kể lại mọi sự, biết Kiều đã trao duyên lại cho Vân... Kim đã thể hiện trách nhiệm và tình cảm sâu nặng khi đón cả gia đình Kiều về ở cùng để tiện bề chăm sóc ông bà thay Kiều. Cần ghi nhận nỗ lực giai đọan ban đầu của chàng trong việc viết thư, thuê mướn người tìm tung tích người thương. Nhưng làm sao tìm được vì nàng ở Lâm Tri mà chàng lại tìm ở Lâm Thanh theo lời nói dối của thằng khốn Mã Giám Sinh kia!

Sau cơn vật vã đau đớn xót thương Kiều, nghe theo lời Vương Ông, Kim đã kết hôn với Vân - một cuộc hôn nhân vì hiếu, vì nghĩa, không vì tình. Rồi theo con đường độc đạo định sẵn, Kim và Vương đã học, đã thi, đã đậu, đã được bổ làm quan về đúng Lâm Tri. Trọn trung trọn hiếu, chàng còn nợ một chữ tình. Khi mọi việc của bản thân và gia đình đã ổn, vẫn còn nhớ thương Kiều, chàng mong tìm lại người xưa. Tin vào giấc mơ của Vân, nghĩ đến khả năng nhầm lẫn hai địa danh Lâm Thanh, Lâm Tri, ông quan Kim Trọng quyết định thăng đường dò hỏi. Lại già họ Đô đã kể vắn tắt cho Kim nghe đọan trường từ khi Tú Bà, Mã Giám Sinh mua Kiều đến khi Kiều về với Thúc Sinh, trốn khỏi nhà Hoạn Thư lại gặp họ Bạc, rồi gặp được người "Hơn nguời trí dũng nghiêng trời uy linh"; và ông ấy đã chỉ cho Kim tìm Thúc Sinh để hỏi tiếp. Thúc Sinh không đề cập gì đến quan hệ của mình với Kiều, chỉ kể cho Kim nghe quan hệ Kiều với Từ Hải, theo đó, Thúc Sinh cũng không biết số phận của nàng ra sao...

Kim "Rắp mong treo ấn tù quan/ Mấy sông cũng lọi mấy ngàn cũng pha/ Dấn mình trong áng can qua/ Vào sinh ra tư họa là thấy nhau" (Nguyễn, 2019, tr. 391). Mấy câu thơ thật hay, bộc lộ khí phách và tình cảm với Kiều, nhưng tiếc thay cũng chỉ mới là ý định, chỉ "rắp mong" chứ chưa phải là hành động thực bởi chàng vẫn còn do dự: "Nhũ̃ng là nấn ná đợi tin" (Nguyễn, 2019, tr. 393). Nấn ná gì nữa hỡi Kim lang? Đã quá muộn màng, rất chi là muộn cho ý tưởng kiếm tìm người yêu xưa vào thời gian năm thứ mười lăm!

May mắn ngẫu nhiên, cả Kim và Vương Quan đều được cải nhậm (thuyên chuyển - bổ nhiệm) về cùng một hướng Phúc Kiến, Chiết Giang - địa bàn hoạt động của Từ Hải. Đến nơi thì đại biến vừa mới xảy ra: "Rằng ngày hôm no giao binh/ Thất co" Tù đã thu linh trận tiền" (Nguyễn, 2019, tr. 393), nàng đã gieo mình xuống sông Tiền Đường! Kim cùng gia đình làm lê̂ chiêu hồn, giải oan cho Kiều. Lại tình cờ ngẫu nhiên, Giác Duyên nhìn thấy bài vị thờ Kiều và đã dẫn đường cho gia đình gặp Kiều nơi nàng tạm nương cửa Phật. Trong buổi gặp nhau sau mười lăm năm ly biệt ấy, Kim không hề 
là tâm điểm mà chỉ là ngoại vi. Chàng không nói lời nào, tác giả không cho Kim nói. Kiều cũng chỉ nhìn lướt qua Kim một cách thản nhiên, hờ hững, vô tình như gặp lại một trong những người quen cũ: "No chàng Kim đó là người ngày xua" (Nguyễn, 2019, tr. 401).

Không muốn về nhà nhưng vâng lời cha Kiều đã trở về nhà; cũng vâng lời cha và nghe theo ý tốt lành khi Vân tự nguyện mở lời trả duyên cho chị, Kiều cũng đã chấp nhận lễ tơ hồng. Nhưng trong đêm động phòng hoa chúc, Kiều chủ động và quyết liệt đề xuất "Đem tình cầm sắt đổi $r a$ cầm cô" (Nguyễn, 2019, tr. 413), dù Kim đã cố bày tỏ một quan niệm mới rất riêng của chàng về việc "lấy hiếu làm trinh" nhưng vẫn không thuyết phục được nàng. Nhìn chung, cả trong đoạn khởi đầu với một tình yêu đẹp và cả trong đoạn kết với một tình bạn tri kỷ, Kiều vẫn luôn mạnh mẽ, quyết liệt, chủ động hơn cả Kim. Đó là sự thật!.

Do ưu ái xây dựng nhân vật chính, dù có dựng xây mối tình Kim-Kiều thơ mộng, nhà thơ đã lãng quên nhân vật Kim Trọng trong hầu hết tình huống cơ bản của cốt truyện. Mười lăm năm lưu lạc của Kiều cũng là mười lăm năm Kim lo gia thất, lập thân, lập nghiệp theo kiểu một nho sĩ hành đạo hiếu trung. Có yếu tố tài tử được nhen nhóm lúc yêu đương vụng trộm buổi ban đầu nhưng khó nói đây là một cặp tài tử-giai nhân. Khi xa Kiều, Kim hết bộc lộ như một kẻ tài tử, chỉ là một người quân tử trung hiếu làm đầu, học hành-thi cử-đỗ đạt-làm quan đúng lộ trình, đúng quy phạm. Xuất hiện chỉ hai lần trong đoạn đầu và đoạn kết, trong chừng $1 / 8$ dung lượng câu thơ, nhưng những câu thơ ây không chỉ hoàn toàn dành cho Kim mà còn dành cho Kiều và các nhân vật khác thể hiện, nói năng, đánh đàn, thơ phú... Và bao hàm trong hai phần mở và kết ấy có cả những lời tuyên ngôn, trữ tình trực tiếp, những quan sát và mô tả khác của Nguyễn Du. Từ khi Kim về hộ tang cho đến khi Kiều được Giác Duyên cứu sống lại, độc giả không biết gì về Kim, Nguyê̂n Du không quan tâm đến Kim.

Dù nhà nghiên cứu khẳng định: "Sau Thúy Kiều, Kim Trọng là nhân vật chính của truyện" (Lê, 1992, tr. 159) nhưng với những gì vừa trình bày trên đây, Kim Trọng cũng chỉ là một nhân vật phụ. Nói theo cách của điện ảnh, Kim chỉ là vai "thứ-chính", nhỉnh hơn Từ Hải một ít mà thôi. Kim Trọng không phải là nhân vật chính của tác phẩm, mối quan hệ Kim-Kiều dù đẹp, tình yêu dù đẹp cũng không phải là chủ đề chính của Truyện Kiều.

\section{THÚC SINH HAM CHƠI, QUEN NÓI DỐI VÀ MAU NƯỚC MẮT}

Khi nghiên cứu nhân vật Kiều và các mối quan hệ, các nhà nghiên cứu không thể không đề cập đến Thúc Sinh. Đó là chàng trai có học; một thương nhân không ham kinh doanh, mảng chơi mà là chơi lớn "Trăm nghìn đổ một trận cười nhu không" (Nguyễn, 2019, tr. 183); là con rể quan thượng thư, Thúc Sinh không yêu vợ, sợ vợ, luôn lép vế cả trong tính toán và mưu mẹo; là một kẻ si tình có con mắt tinh đời đã gặp, đã nhận thấy vẻ đẹp và tài năng của Kiều, đã dan díu và chuộc Kiều, cho Kiều cơ hội tòng lương lần thứ nhất, dù ban đầu chưa yêu nhưng "Trước còn trăng gió sau ra đá vàng" (Nguyễn, 2019, tr. 181)... 
Thúc Sinh là một kẻ cực kỳ mơ hồ. Đến lầu xanh Tú Bà, cặp kè với Kiều bao nhiêu ngày tháng mà còn ngỡ Kiều là con gái Tú Bà: "Cành kia chẳng phải cội này mà $r a$ " (Nguyễn, 2019, tr. 185). Khi vợ nhắc về thăm cha mẹ, Thúc Sinh tưởng có cơ hội thăm Kiều mà không ngờ mẹ con Hoạn Thư đã sắp sẵn kế sâu, kịp thời cho bọn Khuyển Unng đi đường tắt để đốt nhà, bắt Kiều trước khi Thúc Sinh kịp đến nơi...

Thúc Sinh cũng là thánh nói dối, dù không chỉ một mình Thúc Sinh nói dối. Dối vợ để ăn chơi, dối vợ để cưới vợ bé; ngày về nhà bị rơi vào tình thế oái oăm, Thúc Sinh muốn khóc, Hoạn Thư hỏi thì bịa ngay là mẹ chết! Đến một việc hệ trọng như đại tang, đại hiếu mà vẫn mở mồm nói láo được! Mẹ chồng chết sao Hoạn Thư không biết, sao Thúc Ông không báo tin cho sui gia? Hoạn Thư vẫn giả vờ tin, vờ khen chồng có hiếu, mở tiệc tẩy trần, bắt Kiều hầu rượu, hầu đàn. Thúc Sinh giả vờ say để cáo từ cũng không được, đành ngậm bồ hòn làm ngọt... Khi Kim Trọng gặp Thúc Sinh, mặc dù viên lại già họ Đô đã cho Kim biết trước về quan hệ bộ ba Kiều-Thúc Sinh-Hoạn Thư, Thúc Sinh chỉ kể chuyện về Kiều và Từ Hải, không đả động gì đến bản thân mình, làm như không hề quen biết Kiều!

Thúc Sinh là anh chàng giàu nước mắt: Khóc trước mặt cha khi Kiều bị đánh trên công đường mà không biết làm sao cứu đỡ; khóc khi tưởng Kiều đã bị chết cháy; khóc khi gặp lại Kiều ngay tại nhà mình mà không dám nhìn; khóc thầm khi người yêu - vợ bé nay dâng rượu, hầu đàn cho mình trong vai hầu gái của Hoạn Thư; khóc khi "lẻn ra" Quan Âm Các để giãi bày, để nói cho được một câu rất thật mà cũng rất hèn: "Liệu mà xa chay cao bay/ Ai ân ta có ngần này mà thôi”!!!! Đến đó tưởng như Nguyễn Du sẽ hạ màn cho Thúc Sinh kết thúc vai diễn nếu không có cảnh báo ân báo oán mà Từ Hải đã giao toàn quyền cho Kiều. Người đầu tiên mà Kiều trả ơn chính là Thúc Sinh, nhưng chính anh ta cũng sợ toát mồ hôi khi Kiều "Cho gươm mờ đến Thúc lang". Sau vài câu nói về cố nhân, về " $V o ̛$ " chàng quỷ quái tinh $m a$ ", Kiều trả ơn cho Thúc Sinh "Gấm trăm cuốn bạc nghìn cân". Dù sao Thúc Sinh cũng đã tôn trọng, đã cứu chuộc Kiều ra khỏi chốn lầu xanh, đã dành cho nàng danh phận con người dù là lẽ mọn, cho dù Thúc Sinh không bao giờ dám hé răng nói thật với Hoạn Thư như Kiều đã linh cảm và nhắc nhở. Có thể nói, chia tay Kiều ở Quan Âm Các là coi như Thúc Sinh đã chết về tâm hồn; Kiều tặng của cải cho nhà giàu, vậy mà Thúc Sinh vẫn nhận, chẳng khác gì chết thêm lần nữa, trong mắt nàng, trong tâm nàng.

Nguyễn Du đã dành khoảng 1/4 dung lượng Truyện Kiều cho mối quan hệ Thúc Sinh-Thúy Kiều (tất nhiên có chen vào đấy cả Hoạn Thư và một số nhân vật khác) với gần 800 câu thơ (từ câu 1275 đến câu 2034) chứng tỏ sự quan tâm sâu sắc đến tình cảm Thúy Kiều-Thúc Sinh, đến quan hệ Thúc Sinh-Thúy Kiều-Hoạn Thư hơn cả quan hệ Kim-Kiều và Kiều-Từ Hải. Xét những nhân vật phụ có liên quan đến Kiều, ở một góc cạnh nhất định, Thúc Sinh vẫn là nhân vật gây được ấn tượng độc đáo cho người đọc, người nghe và rất đáng quan tâm khi nghiên cứu Truyện Kiều.

\section{CÓ HAY KHÔNG HÀNH VIỆN CỦA BẠC BÀ, BẠC HẠNH?}

Tuy là nhân vật phụ, rất phụ nhưng cả Bạc Bà và Bạc Hạnh đều được các nhà nghiên cứu nhắc tới trong vai những kẻ đày đọa Kiều - nhân vật chính của tác phẩm. 
Vậy trong mắt các nhà nghiên cứu thì Bạc Bà, Bạc Hạnh là ai? Có đúng là cái nhà chứa - hành viện (hàng viện) của Bạc Bà, Bạc Hạnh là nơi Kiều sa vào thanh lâu lần thứ hai không?

- Nhà nghiên cứu thứ nhất đã nhận định: "Giác Duyên đã "mời" Kiều ra khỏi nhà để phải rơi vào nhà chứa của Bạc Bà, Bạc Hạnh”; “...cuối cùng xô đẩy Kiều đển nhà chứa của Bạc Bạc Bà, Bạc Hạnh”; “...những cuộc gặp gỡ trong nhà chứa cao cấp của Tú Bà, hay hạ lưu như hành viện của Bạc Bà, Bạc Hạnh" (Lê, 1992, tr. 83, 148, 151).

- Nhà nghiên cứu thứ hai khẳng định: "Kiều đã... hai lần làm đĩ (ở nhà Tú Bà và ở nhà Bạc Bà)" (Phan, 2001, tr. 74).

- Nhà nghiên cứu thứ ba cũng khẳng định chắc chắn như thế: "Trong hành viện của Bạc Bà, Bạc Hạnh, nàng gặp một con người...”; “Ở đây nhà chứa có cái to như lầu xanh của Tú Bà, có cái bé như hành viện của Bạc Bà, Bạc Hạnh" (Nguyễn, 2004, tr. 355, 375)...

Một khi các nhà Kiều học đã nhất thống đến thế thì chúng ta chỉ việc nương theo quán tính hay nên đọc lại Truyện Kiều thêm lần nữa, xem thử Nguyễn Du thể hiện Bạc Bà, Bạc Hạnh như thế nào trong mối quan hệ với Kiều? Về hai nhân vật này nhà thơ không viết nhiều, chắc cũng nên trích nhiều hơn một chút để rõ ý Nguyễn Du.

Biết Kiều trốn khỏi Quan Âm Các, lại còn ăn cắp đồ thờ của Hoạn Thư, Giác Duyên bộc lộ lo lắng, nửa thương nửa sợ liên lụy nên đã gửi gắm Kiều cho nhà họ Bạc mà không hề biết người ta bản chất như thế nào? Nguyễn Du đã giới thiệu Bạc Bà qua lời Giác Duyên:

Giác Duyên nghe nói rụng ròi,

Nưa thương, nưa sợ bồi hồi chẳng xong.

...Có nhà họ Bạc bên kia,

Am mây quen lối đi về dầu huoong.

Nhắn sang dặn hỏi mọi đương,

Dọn nhà hãy tạm cho nàng trú chân.

(Nguyễn, 2019, tr. 283)

Trong phạm vi 27 câu thơ tiếp theo (từ 2085 đến 2112), nhà thơ khẳng định tính cách xấu xa của Bạc Bà, âm mưu sắp đặt cuộc hôn nhân giả, nhanh chóng ép duyên Kiều với cháu mình, qua đó tác giả khắc họa bản chất Bạc Bà và để cho Bạc Bà hót ca đức độ "thật thà" của Bạc Hạnh:

Nhũng mùng được chốn an thân,

Vội vàng nào kịp tính gần tính xa. 
Nào ngờ cũng tổ bợm già,

Bạc Bà hoc với Tú Bà đồng môn!

Thấy nàng lạt phấn nhàm son,

Mùng thầm được mối bán buôn có lời.

Hu không đặt bỏ nên lời,

Nàng đà lớn sợ rụng rời lắm phen.

Mụ càng xua đuổi cho liền,

Lấy lời hung hiểm ép duyên Châu Trần.

Này chàng Bac Hanh cháu nhà,

Cùng trong thân thích ruột rà chăng ai.

Cửa hàng buôn bán châu Thai,

Thưc thà có môt đơn sai chẳng hề.

Thế nào nàng cũng phải nghe,

Thành thân rồi sẽ liệu về châu Thai.

(Nguyễn, 2019, tr. 283-284)

Không còn lối thoát nào khác, Kiều đành nhắm mắt, dầu nàng linh cảm một sự bất an nhưng vẫn yêu cầu Bạc Hạnh phải thề ước:

Nàng càng mặt ủ mày chau,

Càng nghe mụ nói càng đau như dần.

Nghĩ mình túng đất sảy chân,

Thế cùng nàng mới xa gần thở than:

Chứng minh có đất có trời,

Bấy giờ vượt bể ra khơi quản gì?

(Nguyễn, 2019, tr. 287)

Đến đây, Bạc Hạnh mới xuất hiện vỏn vẹn trong phạm vi 17 câu (từ câu 2128 đến câu 2144):

Được lời mụ mói ra đi,

Mách tin ho Bac tức thì sắm sanh.

Môt nhà don dep linh đình, 
Quét sân đăt trác rửa bình thắp nhang.

Bac Sinh quì xuống vôi vàng.

Quá lời nguyên hết Thành hoàng Thổ công.

Truớc sân lòng đã giãi lòng,

Trong màn làm lễ tơ hồng kết duyên.

Thành thân mới rước xuống thuyền,

Thuận buồm một lá xuôi miền châu Thai.

Thuyền vì̀a đồ bến thảnh thoi,

Bac sinh lên trước tìm noi moi ngày.

Cüng nhà hàng viên xưa nay,

Cüng phường bán thit cũng tay buôn nguời.

Xem người định giá vì̀a rồi,

Mối hàng môt đã ra mười thì buông.

Mươn người thuê kiêu ruớc nàng,

Bac đem măt bac kiếm đường cho xa!

(Nguyễn, 2019, tr. 289)

Rõ ràng Bạc Hạnh là dân chơi kiêm con buôn, mà là buôn người; Bạc Bà chủ mưu, Bạc Hạnh thực hiện một cuộc hôn nhân giả đề lừa Kiều. Bạc Hạnh gần giống Mã Giám Sinh, nhưng Mã Giám Sinh mua người theo lệnh Tú Bà, giả vờ thề ước, kết hôn để cướp đi sự trong trắng của Kiều, cùng Tú Bà đưa Kiều vào lầu xanh lần thứ nhất. Mã Giám Sinh, Sở Khanh tiếp tay, phụ giúp cho Tú Bà hành hạ, đày đọa Kiều. Còn Bạc Hạnh đã "tìm nơi mọi ngày” và khi bán Kiều được giá, Bạc Hạnh liền bỏ trốn, giúp Bạc Bà thực hiện trót lọt một âm mưu.

Từ đây, Kiều bị rơi vào lầu xanh lần thứ hai, đúng như nhà thơ đã viết là "thanh lâu hai lượt", nhưng thanh lâu (hành viện, hàng viện) của ai? Chắc chắn không phải là của Bạc Bà, Bạc Hạnh mà là một mụ khác "cũng phường bán thịt":

Kiệu hoa đặt trước thềm hoa,

Bên trong thấy môt mu ra vội vàng.

Đưa nàng vào lạy gia đường,

Cũng thần mày trắng cũng phường lầu xanh!

(Nguyễn, 2019, tr. 291)

Tác giả dành 14 câu thơ tiếp theo để cảm thán về thân phận (từ câu 2150 đến 2162) là những lời nguyền rủa, than trách đớn đau cho phận người, lời đau thương ấy của nàng Kiều cũng chính là của Nguyễn Du: 
Chém cha cái số hoa đào,

Gõ ra rồi lại buộc vào nhu chơi!

Nghĩ đời mà ngán cho đời,

Tài tình chi lắm cho trời đất ghen!

Tiếc thay nuớc đã đánh phèn,

Mà cho bùn lại vẩn lên mấy lần!

Hồng quân với khách hồng quần,

Đã xoay đến thế, còn vần chura tha.

Lớ tù̀ lạc bước bước ra,

Cái thân liều nhũng tù̀ nhà liều đi.

Đầu xanh đã tội tình chi?

Má hồng đến quá nưa thì chua thôi.

(Nguyễn, 2019, tr. 291)

Các nhà nghiên cứu thường ghép ba nhân vật thành chuỗi Tú Bà-Bạc Bà-Bạc Hạnh nhưng thực chất chủ nhân của cái hành viện này là mụ chủ khác. "Bạc Bà hoc với Tú Bà đồng môn", nhưng trong tác phẩm này, lầu xanh (hành viện, hàng viện) không phải của Bạc Bà, Bạc Hạnh. Nguyễn Du cũng không hề mô tả gì về việc "hành nghề" của nàng tại đó mà chỉ viết đúng hai câu cho biết Kiều cam phận:

Biết thân chạy chẳng khỏi trời,

Cũng liều mặt phấn cho rồi ngày xanh.

(Nguyễn, 2019, tr. 293)

Và ngay sau đó, từ câu thơ 2165, tác giả đột ngột chuyển ngay sang tình huống đặc biệt - Người anh hùng giải phóng đời Kiều đã xuất hiện:

Lần thâu gió mát trăng thanh,

Bồng đâu có khách biên đình sang chơi.

(Nguyễn, 2019, tr. 293)

Các nhà nghiên cứu mà chúng tôi vừa trích trên đây và đa số bạn đọc khi trả lời phỏng vấn nhanh của tác giả bài viết này qua Zalo, đều đã nhầm cái lầu xanh lần hai mà Kiều rơi vào là của Bạc Bà, Bạc Hạnh. Hai kẻ khốn nạn này đã bán Kiều cho chủ chứa khác. Xong thương vụ này, chúng hết vai diễn. Nguyễ̂n Du chỉ cho chúng tái xuất lần nữa để nhận án tử được Kiều tuyên, án tử dành cho những kẻ đã dám thề bồi mà lại nuốt lời... Sai sót vừa nêu tuy không lớn, nhưng với một tác phẩm lớn như Truyện Kiều thì không đáng để xảy ra trong một thời gian dài như thế, trong những công trình đáng tin cậy và được trích dẫn nhiều như thế. Thật đáng tiếc lắm thay!. 


\section{THAY LÒंI KẾT}

Trên đây người viết đã khảo sát một số nhân vật phụ trong Truyện Kiều. Đó là Vương Quan - một ông quan bàng quan với mọi gia sự; là nhân vật đáng trách về phương diện đạo lý, tình nghĩa trong gia đình, nhất là với Kiều - người chị đã tự bán mình chuộc cha và em. Kim Trọng cũng chỉ là một nhân vật phụ, một tình nhân lãng mạn trong phần mở đầu; một nhân vật bị tác giả lãng quên trong suốt quá trình diễn biến cốt truyện; được tái xuất trong phần cuối tác phẩm với sự thụ động cả trong việc tìm kiếm và đoàn viên tái hợp với Kiều. Thúc Sinh trong mối quan hệ với cha, với Hoạn Thư, với Kiều đều có sự do dự, lúng túng, bất nhất, đáng giận, đáng trách, đáng thương, có bộc lộ một nội tâm biến động, một thay đổi xét về thi pháp nhân vật. Bạc Bà, Bạc Hạnh cần được nhìn nhận đúng là những kẻ đã đẩy Kiều vào lầu xanh lần thứ hai nhưng lầu xanh ấy không phải của chúng. Người đi sau không nên sao chép, dẫn theo, nhận thức theo quán tính khi tiếp nhận các ý kiến chưa chính xác trong các chuyên khảo, chuyên luận về kiệt tác Truyện Kiều.

Thúy Kiều là nhân vật chính duy nhất của Truyện Kiều đã được xây dựng thành công, được tất cả các nhà nghiên cứu chuyên và không chuyên về văn học trung đại Việt Nam đặc biệt quan tâm, được muôn người muôn đời thương xót. Các nhân vật phụ khác xuất hiện ít hoặc rất ít đều có vai diễn của mình, đều thực hiện chức năng mà tác giả trao cho, đều bộc lộ phẩm chất và hành động mà trong bài viết này chúng tôi đề cập chưa đầy đủ.

Truyện Kiều là một truyện thơ tiêu biểu nhất, xét về phương diện tự sự chỉ có duy nhất một nhân vật chính được tác giả chăm chút thành công và để lại ấn tượng sâu sắc trong lòng người tiếp nhận. Với hàng nghìn câu thơ hay, rất cần thiết đầu tư nghiên cứu Truyện Kiều về cảm xúc thơ, chất thơ, câu thơ, thể thơ, thủ pháp và các khía cạnh khác từ phương diện trữ tình của truyện-tho thì mới trọn vẹn và tương xứng với tài năng thi ca của Nguyễn Du. Trước sau và mãi mãi, tiên sinh vẫn là một nhà thơ, một Đại thi hào của nền thi ca Việt Nam.

\section{TÀI LIỆU THAM KHẢO}

Lê, Đ. K. (1992). Truyện Kiều và chủ nghĩa hiện thực. NXB Hội Nhà văn TP.HCM.

Nguyễn, D. (2019). Truyện Kiều (Ban Văn bản Truyện Kiều - Hội Kiều học Việt Nam hiệu khảo, chú giải). NXB Trẻ.

Nguyễn, V. D. (2004). Phuơng pháp luận nghiên cưu văn học. NXB Khoa học xã hội.

Phan, N. (2001). Tìm hiểu phong cách Nguyến Du trong Truyện Kiều. NXB Thanh Niên. 